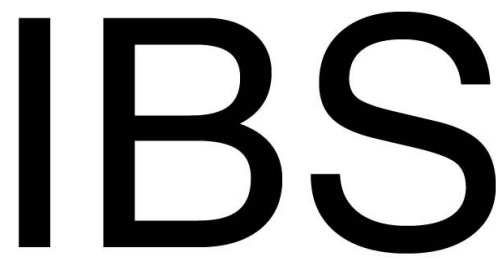

RESEARCH PROGRAM ON POPULATION PROCESSES

INSTITUTE OF BEHAVIORAL SCIENCE -

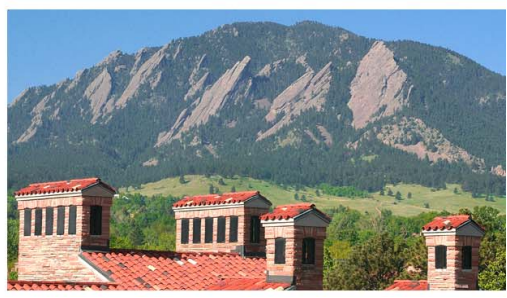

WORKING PAPER

\title{
Applying Model Migration Schedules to Represent Age-Specific Migration Flows
}

James Raymer

Andrei Rogers

February 2006 


\section{Applying Model Migration Schedules to Represent Age-Specific Migration Flows}

James Raymer ${ }^{\dagger}$

Andrei Rogers ${ }^{\ddagger}$

February 2006

Acknowledgments: This work was supported by the National Institute of Child Health and Human Development and the National Science Foundation.

Corresponding author and contact information:

James Raymer; Division of Social Statistics; School of Social Sciences; University of Southampton;

Southampton SO17 1BJ; E-mail: Raymer@soton.ac.uk; Telephone: +44 (0) 238059 2935; Fax: +44 (0) 23 80593858

${ }^{\dagger}$ Division of Social Sciences, School of Social Sciences, University of Southampton, Southampton, SO17 1BJ, United Kingdom, E-mail: Raymer@soton.ac.uk

${ }^{\ddagger}$ Population Program, Institute of Behavioral Sciences, University of Colorado, Boulder, CO 80309-0484, United States, E-mail: Andrei.rogers@colorado.edu. 


\section{Contents}

1. Introduction

2. Conceptual Framework: Regularities in the Age Patterns of Migration

$2.1 \quad$ Explaining the Regularities

2.2 Describing the Regularities: Interstate Migration in the U.S. West, $1985-1990$

3. Fitting Multiexponential Model Schedules to Age Patterns of Migration

4. Modeling Families of Age-Specific Migration

5. Discussion and Conclusion 


\section{Introduction}

Internal migration and national population redistribution are universal phenomena experienced by all nations. But are their patterns, antecedents, and consequences similar worldwide? Are there observable regularities in age pattern exhibited by origin-destinationspecific rates of migration? Do such regularities hold all over the world? Why do they? How might demographers take advantage of them? At the International Institute for Applied Systems Analysis in Austria, demographers first began to address these questions in the late 1970’s by assembling an international data base on contemporary internal migration in the developed nations and successfully fitting these data with a mathematical function, since called the RogersCastro multiexponential model migration schedule (Rogers and Castro 1981a).

Rogers and Castro (1981a) put forward three families of multiexponential model migration schedules: a standard 7-parameter model, a 9-parameter elderly post-retirement migration model, and an 11-parameter elderly retirement peak model. Several years later, Rogers and Watkins (1987) added a 13-parameter elderly retirement peak plus post-retirement model ${ }^{*}$. Their analysis of over 500 age profiles of migration found throughout the more developed world made the convincing argument that migration has strong regularities in age patterns, much like fertility and mortality. Stylized schedules of these four families are set out in Figure 1. The most commonly found schedule is the standard schedule, comprised of three components: a constant, a negative exponential curve representing the pre-labor force ages, and a double exponential (unimodal) curve representing the labor force ages. Multiexponential model migration schedules have since been used for describing, smoothing, and inferring age-specific migration patterns in a wide variety of contexts (e.g., Bates and Bracken 1982, 1987; Holmberg 1984; Kawabe 1990;

\footnotetext{
* See also: Rogers A and JS Little. 1994. Parameterizing age patterns of demographic rates with the multiexponential model schedule. Mathematical Population Studies, 4(3):175-194.
} 
Liaw and Nagnur 1985; Potrykowska 1986; Rogers 1988; Rogers and Rajbhandary 1997; Rogers and Raymer 1999). It seems evident, in consequence, that the multiple parameter model migration schedule, adequately describes the regularities in age profile exhibited by internal migration flows in the developed world today. But what about migration in the less developed countries? And historical migration patterns? And patterns of international migration? What commonalities in life course dynamics might explain the widespread observed regularities in migration age patterns? How can such regularities be drawn on to infer age-specific migration rates in poor countries lacking established data collection systems? How can they be used to improve the quality of collected data? These are the questions that motivate the research described in this chapter. 
Standard

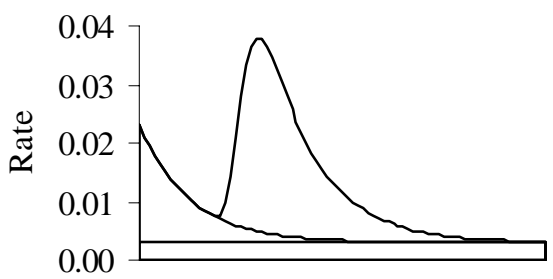

$\begin{array}{lllllllll}0 & 10 & 20 & 30 & 40 & 50 & 60 & 70 & 80\end{array}$

Age

Elderly Post-Retirement

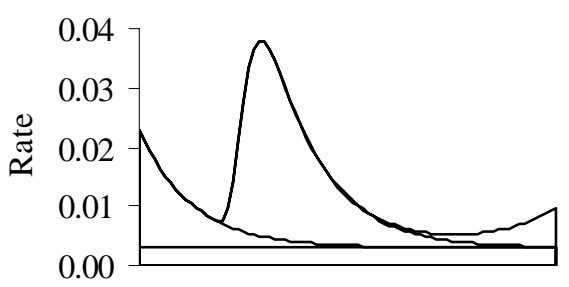

$\begin{array}{lllllllll}0 & 10 & 20 & 30 & 40 & 50 & 60 & 70 & 80\end{array}$

Age
Elderly Retirement Peak

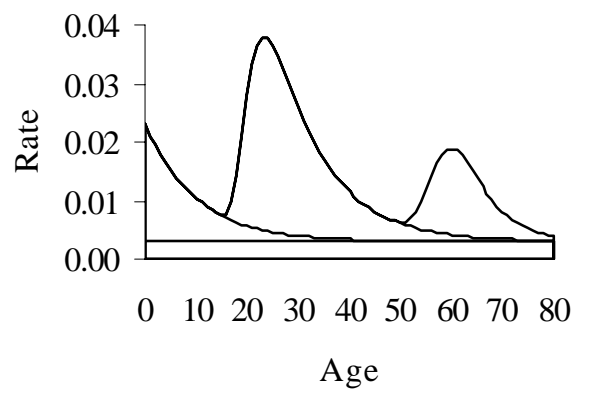

Elderly Ret. Peak and Post-Ret.

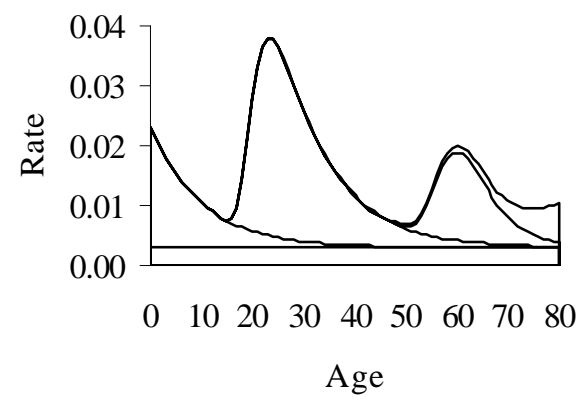

Figure 1. The four main families of multiexponential model migration schedules: standard, elderly retirement peak, elderly post-retirement upslope, and elderly retirement peak and postretirement upslope

Families of model migration schedules are used in this paper to demonstrate the regularities found in age patterns of migration. We begin with a review of the life course events that give rise to the age patterns, and then we describe how these events are reflected in the multiexponential model migration schedule. Second, we describe the observed 1985-1990 age profiles of interstate migration in the U.S. West region. Third, we illustrate a few estimated model schedules, and fourth, we fit a number of age patterns using various families of model 
migration schedules. Finally, the applicability of this approach is discussed in a more general migration modeling context.

\section{Conceptual Framework: Regularities in the Age Patterns of Migration}

\subsection{Explaining the Regularities}

Empirical schedules of age-specific rates exhibit remarkably persistent regularities in age pattern. Mortality schedules, for example, normally show a moderately high death rate immediately after birth, after which the rates drop to a minimum between ages 10 and 15, then increase slowly until about age 50, and thereafter rise at an increasing pace until the last years of life. Fertility rates generally start to take on nonzero values at about age 15 and attain a maximum somewhere between ages 20 and 30; the curve is unimodal and declines to zero once again at some age close to 50. Similar unimodal profiles may be found in schedules of first marriage, divorce, and remarriage. The most prominent regularity in age-specific schedules of migration is the high concentration of migration among young adults; rates of migration also are high among children, starting with a peak during the first year of life, dropping to a low point at about age 16, turning sharply upward to a peak near 20 to 22, and declining regularly thereafter, except for a possible slight hump at the onset of retirement and possibly an upward slope after that hump.

Underlying these persistent regularities in the age patterns of migration are a collection of different cause-specific age patterns (Rogers and Castro 1981b). For example, migrations due to marriage and education are concentrated between the ages of 10 and 30 and are essentially unimodal in age profile. Migrations caused by change of employment and moving closer to the place of work have profiles that are bimodal, with local peaks during infancy and during the 
early years of labor-force participation. The age profiles of housing reasons for migration are similar to those of the aggregate migration schedule, exhibiting roughly the same peaks: during infancy, during the early years of labor force participation, and at retirement. Finally, health is apparently an important cause of migration only for the elderly.

The different cause-specific age patterns may be interpreted within a life course framework in which individuals pass through different states of existence (Elder 1985). Starting with birth and then entry into the educational system at the elementary level, the "passage" may also include entry into military service or university, marriage, multiple entries into and withdrawals from the labor force, perhaps divorce and remarriage, retirement, death of spouse, and moves to enter sanatoria or to rejoin relatives. Life course analysis focuses on the processes of change and ultimately seeks to explain such change.

The formal demography of migration and population redistribution views interregional population transfers as a collection of independent individual movements. Yet it is widely recognized that a large fraction of total migration is accounted for by individuals whose moves are dependent on those of others, for example, children migrating with their parents, wives with their husbands, grandparents with their children. Indeed, family migration is such a wellestablished phenomenon that Ryder (1978) has even suggested its use as a criterion for identifying family membership: a family comprises of those individuals who would migrate together. Hence, to the extent that migration is undertaken by families as a unit, the age composition of migrants tells us something about family patterns.

To better understand the influences that family and dependency relationships have on migration age compositions, Castro and Rogers (1983a and 1983b) have illustrated how by disaggregating migrants by age, sex, and dependent/independent categories it is possible to 
illustrate a number of ways in which the aggregate age profile of migration is sensitive to relative changes in dependency levels and in rates of natural increase and mobility. Viewing the migration process within a framework of dependent and independent movements allows one to observe, for example, that if the independent component is mainly comprised of single persons, then the associated dependent migration may be insignificant in terms of its relative share of the total migration. On the other hand, if migration tends to consist primarily of family migration, then the share of dependent children may become a very important component of the aggregate migration age pattern. In short, just as observed population age compositions reflect particular characteristics of past fertility and mortality regimes, so do observed migration age compositions reflect key aspects of a population's age composition. The reverse relationship also holds true. Just as observed migration age compositions reflect particular age compositions of populations, so population compositions influence key aspects of migration age compositions (Little and Rogers 2006).

\subsection{Describing the Regularities: Interstate Migration in the U.S. West, 1985-1990}

The age-specific flows of interstate migration observed in the West region during the 1985-1990 period, are examined in this section to illustrate how the observed regularities in age structure can be described. For comparison purposes, the age patterns have been standardized to unit area, denoted by $\mathrm{N}_{\mathrm{ij}}(\mathrm{x})$, where $\mathrm{x}$ represents the age at the beginning of an age interval and at the time period. For example, $\mathrm{N}_{\mathrm{ij}}(20)$ denotes migrants ages 20-24 in 1985. Two age profiles are presented in Figure 2: (1) all interstate migration in the U.S. West region and (2) migration from 
abroad to the U.S. West region. This graph shows that migrants from abroad (i.e., immigrants) migrated at younger ages than did interstate (i.e., domestic) migrants ${ }^{\dagger}$.

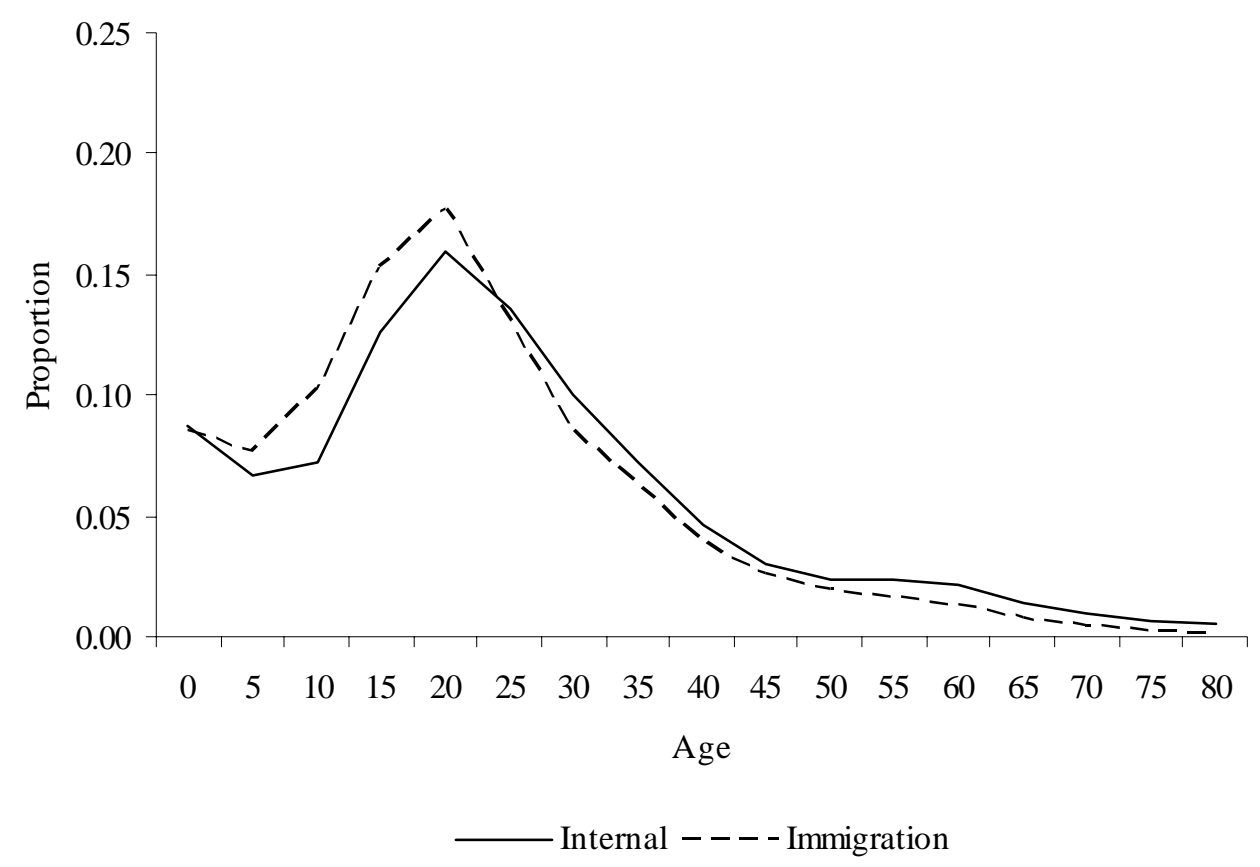

Figure 2. Age profiles of U.S. interstate migration and immigration, 1985-1990: U.S. West region

The internal migration age profiles set out in Figure 3 show that, overall, in-migrants and out-migrants had similar shapes. The main differences can be found in older age groups (i.e., ages 50-74) and in age groups before age 30. Migration to Arizona, Nevada, and Oregon exhibited small retirement peaks, whereas migration to Hawaii and Utah exhibited relatively young labor force peaks and no retirement peaks. Differences found in the internal out-migration profiles include a small retirement peaks exhibited by California and Arizona and a very sharp labor force peak at ages 20-24 exhibited by Hawaii.

\footnotetext{
${ }^{\dagger}$ The corresponding observed age profile of emigrants is not available.
} 
After examining all 196 of the age profiles of migration between internal and external locations for the U.S. West, ${ }^{\ddagger}$ four distinct age profiles were found: (1) a standard age profile, (2) a young standard age profile, (3) an old standard age profile, and (4) an elderly retirement peak age profile. The "standard" age profile of migration is one that contains a labor force peak and no retirement peak (i.e., flat or down-sloping in the older age groups). The peak of this labor force curve centers on the 20-24 age group. Schedules that center on the 15-19 age group, are termed "young” and schedules that center on 25-29 or 30-34 age groups are termed "old.” The "elderly retirement peak" age profile of migration is one that contains both a labor force peak and a peak around ages 50-69 years (i.e., retirement years). Examples of each of the four observed age profiles are set out in Figure 4. They represent age-specific migration (standardized to unit area) from California to Utah (i.e., “young”), Colorado (i.e., “standard”), Montana (i.e., “old”), and Arizona (i.e., "retirement peak").

\footnotetext{
‡ $196=15$ origins $* 14$ destinations (excluding abroad) -14 non-migrants (diagonal).
} 
In-Migration

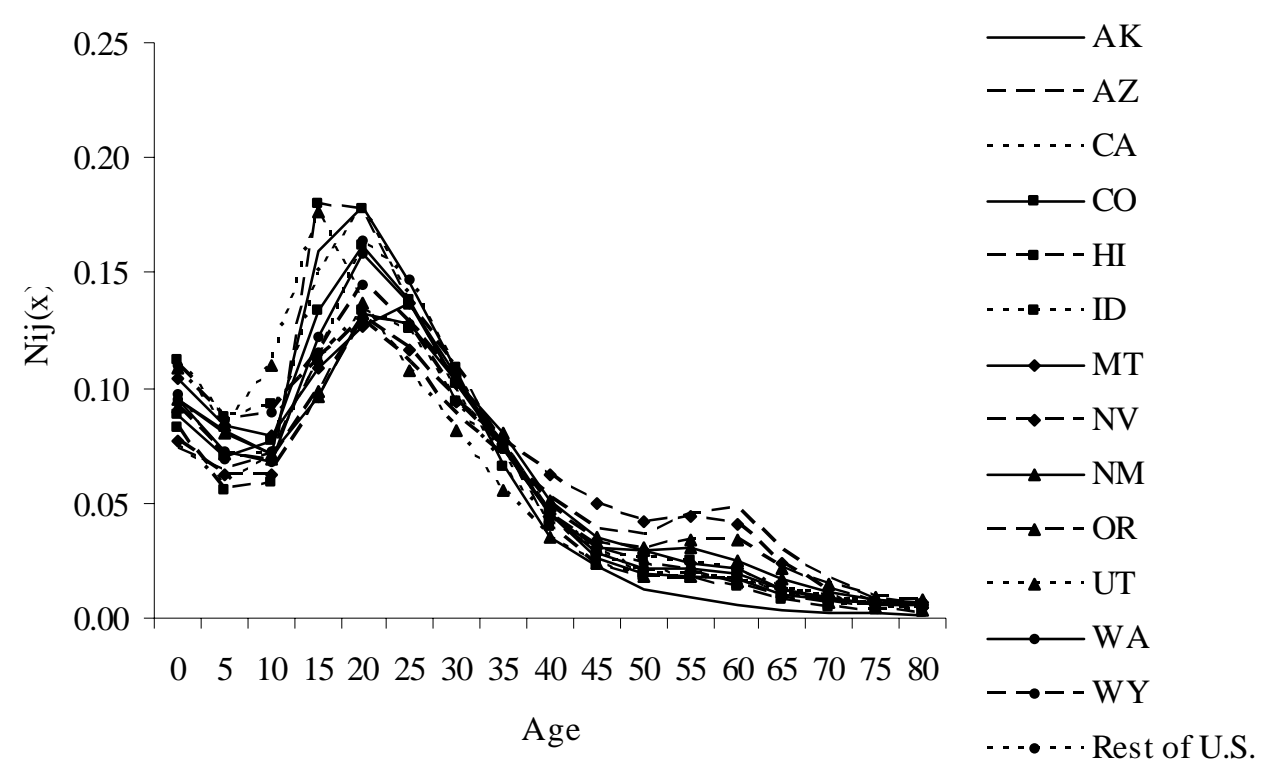

Out-Migration
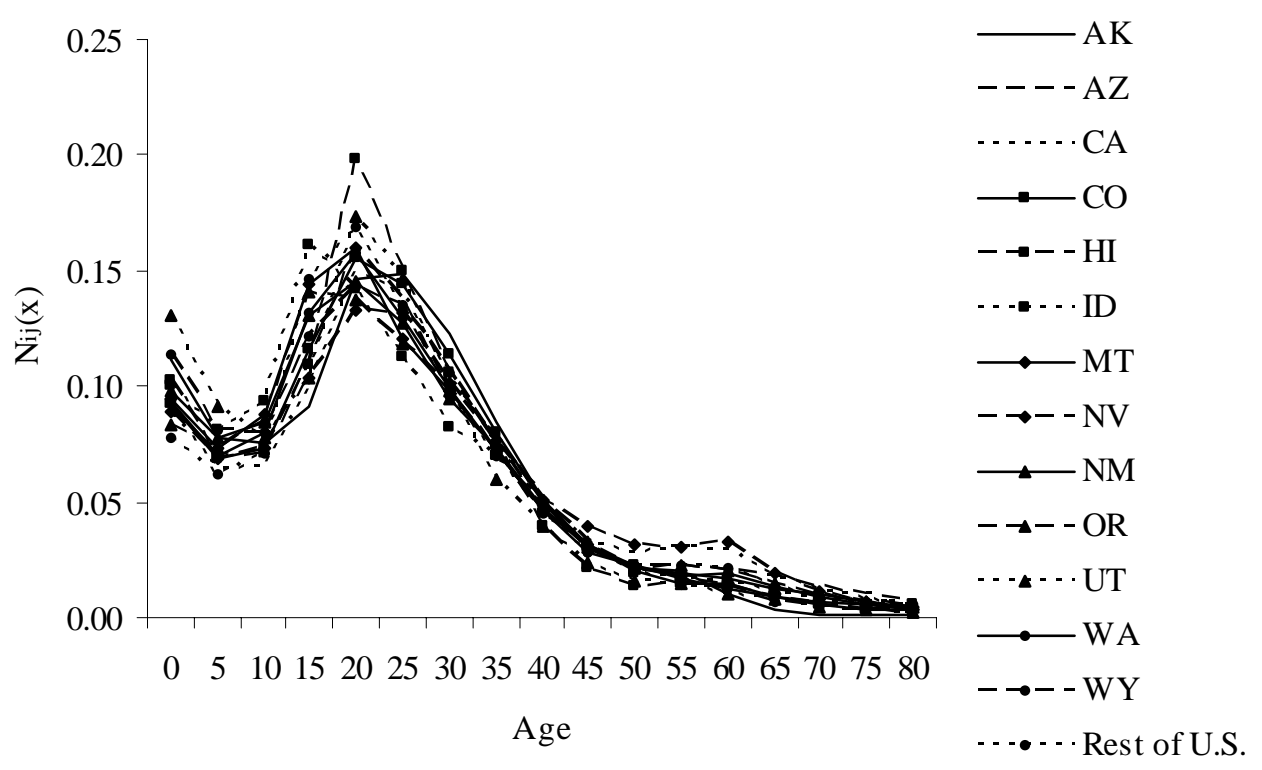

Figure 3. Age profiles of interstate in-migration and out-migration in the U.S. West, 1985-1990 


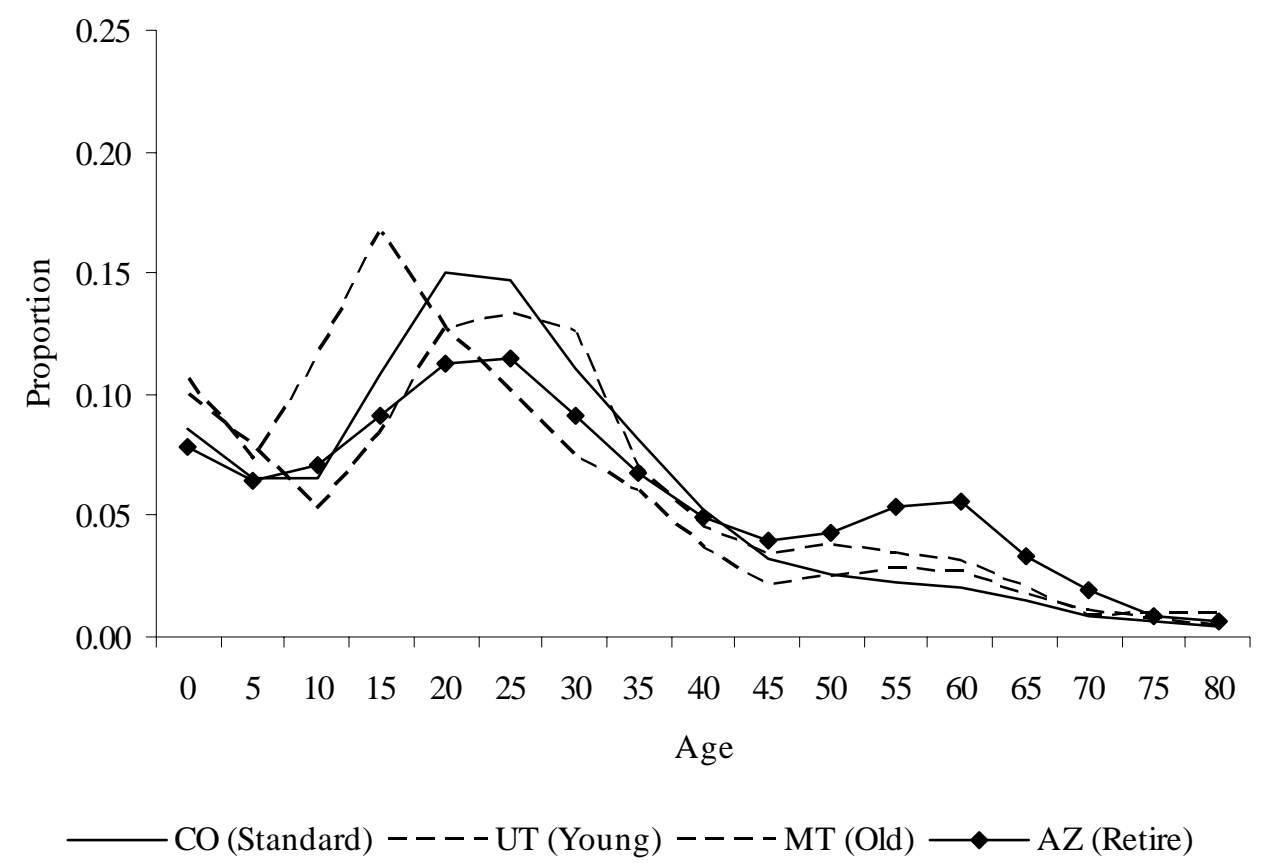

Figure 4. Standard, young, old, and elderly retirement migration profiles: Age profiles of migration from California to Colorado, Utah, Montana, and Arizona, 1985-1990

The typology for the 196 observed migration flows are set out in Figure 5. Sixty percent (118 flows) of the migration flows exhibited the "standard" age profile of migration. These age patterns were clearly represented in the migration patterns from and to Washington. Eighteen percent (35 flows) of the migration flows exhibited the "old standard" age profile. These age profiles were representative of migration from Alaska and Wyoming or migration to Montana. Seventeen percent (34 flows) of the migration flows exhibited the "young standard" age profile. Migration patterns from Idaho or to Utah exhibited these age profiles. Finally, five percent (9 flows) of the migration flows exhibited the "elderly retirement" age profile of migration. The age patterns were representative of migration to Arizona or from California. 


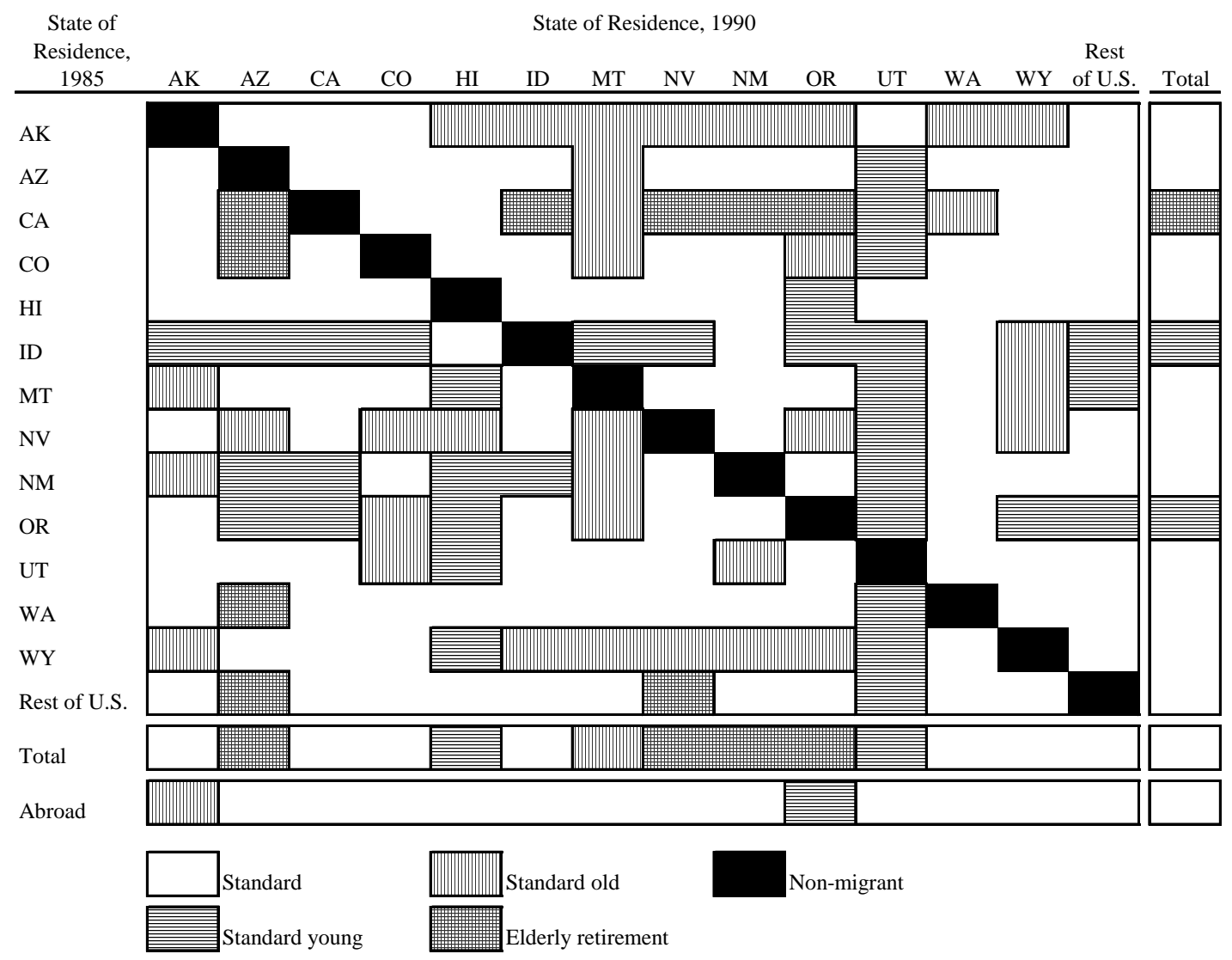

Figure 5. The age profiles of interstate migration in the U.S. West, 1985-1990

\section{Fitting Multiexponential Model Schedules to Age Patterns of Migration}

The overall age profile of interstate migration in the United States, observed during the 1985-1990 period, is set out in Figure 6. During this time, there were about 7.6 million persons who resided in a different state in 1990 than they did in 1985 (U.S. Census Bureau 1993). Fiftytwo percent of these migrants were between the ages of 15 and 34 years. The age group with the smallest number of migrants was the last age group (80+) with 39 thousand persons. The age group with the largest number of migrants was the 20-24 year old age group with 1.2 million persons. 


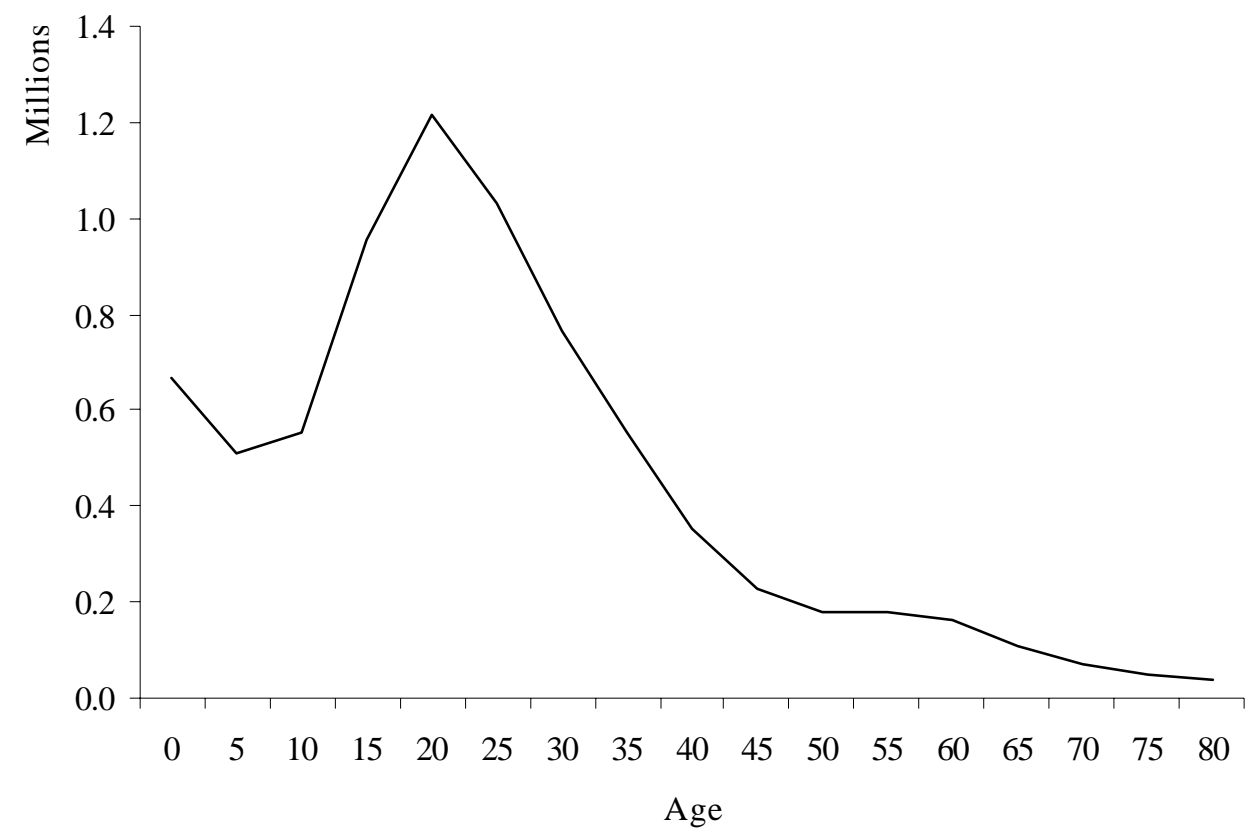

Figure 6. Observed age-specific interstate migration totals in the U.S., 1985-1990

The age-specific counts of migrants presented in Figure 6 can be fitted by a sevenparameter multiexponential model migration schedule having the form:

$$
\hat{\mathrm{n}}_{++}(\mathrm{x})=\mathrm{a}_{0}+\mathrm{a}_{1}^{-\alpha_{1} \mathrm{x}}+\mathrm{a}_{2}^{-\alpha_{2}\left(\mathrm{x}-\mu_{2}\right)-\exp \left[\lambda_{2}\left(\mathrm{x}-\mu_{2}\right)\right]} .
$$

The parameters resulting from fitting the schedule to the age-specific data in Figure 6 are:

$$
\hat{\mathrm{n}}_{++}(\mathrm{x})=48,099+611,131^{-0.048 \mathrm{x}}+2,261,105^{-0.100(\mathrm{x}-17.472)-\exp [0.175(\mathrm{x}-17.472)]} .
$$


The schedule had a $\mathrm{R}^{2}$ of 0.9965 . All of the t-statistics associated with the coefficients are significant at the 0.05 level, with the exception of the one associated with the constant $\mathrm{a}_{0}$. For this example, the model migration schedule predicts the observed data nearly perfectly.

The parameters of the model migration schedule fit to the standardized version of the age-specific counts set out in Figure 6 are:

$$
\hat{\mathrm{N}}_{++}(\mathrm{x})=0.006+0.080^{-0.048 \mathrm{x}}+0.297^{-0.100(\mathrm{x}-17.472)-\exp [0.175(\mathrm{x}-17.472)]}
$$

Notice that the $\alpha_{1}, \alpha_{2}, \mu_{2}$, and $\lambda_{2}$ parameters remain the same. The $\mathrm{a}_{0}, \mathrm{a}_{1}$, and $\mathrm{a}_{2}$ are level parameters, whereas the other parameters are shape parameters. In this paper, the modeling focuses on the standardized schedules of age-specific migration flows (i.e. scaled to unit area under the curve.) There are two reasons for focusing on standardized schedules of counts (as opposed to rates or flows). The first reason is that a standardized schedule can be multiplied by an index of aggregate level to obtain the age-specific flows. This relationship makes the estimation process much simpler because it breaks up the modeling into two distinct stages: levels and shapes. Once the aggregate flows are obtained, the age patterns can be predicted readily. The second reason is that age-specific data are sometimes provided, but they do not always match the data for the reported in- and out-migration flows. By focusing on the standardized schedule, one puts more weight on the reported age profile, not on the underlying numbers. This allows one to maintain consistency in the estimation process in the sense that the differences between the in-migration levels and the out-migration levels are equal to the aggregate net migration levels. 
Next, consider the age pattern of migration from California to Arizona exhibited during the 1985-1990 period (Figure 7). Here, there were 136 thousand migrants. Forty-one percent of the migrants were between the ages of 15 and 34 years. The age group with the smallest number of migrants was the last age group (80+) with 849 persons. The age group with the largest number of migrants was the 25-29 year old age group with 15.7 thousand persons. What is interesting about these data is that 14 percent of the migrants were between the ages of 55 and 69 years. In the data set out in Figure 2, only 6 percent of the migrants were between the ages of 55 and 69 years.

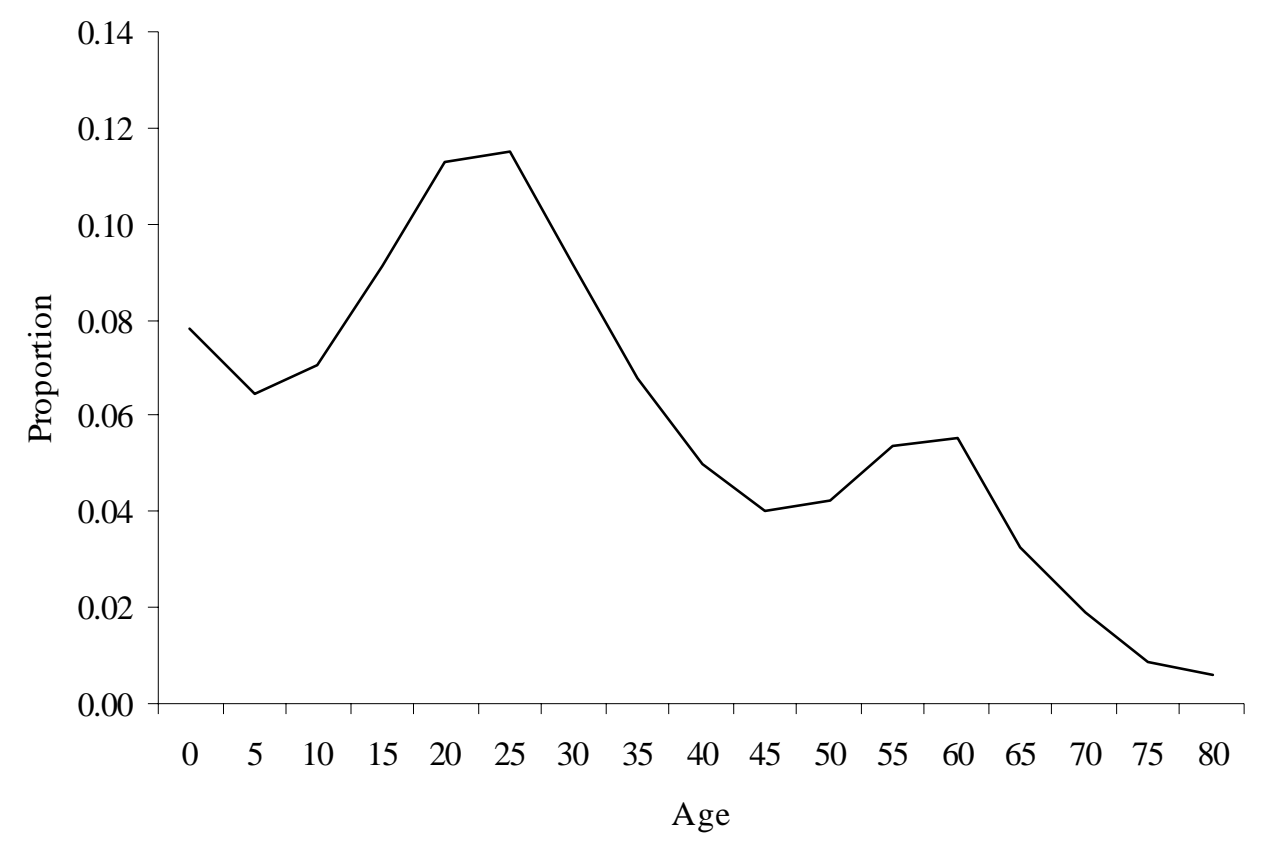

Figure 7. Observed age profile of migration from California to Arizona, 1985-1990 
To model the age profile set out in Figure 7, one needs a more complicated model than that set out in Equation 1. Specifically, an additional unimodal curve is needed to capture the higher propensity exhibited by elderly migrants, i.e.,

$$
\hat{\mathrm{N}}_{\mathrm{CA}, \mathrm{AZ}}(\mathrm{x})=\mathrm{a}_{0}+\mathrm{a}_{1}^{-\alpha_{1} \mathrm{x}}+\mathrm{a}_{2}^{-\alpha_{2}\left(\mathrm{x}-\mu_{2}\right)-\exp \left[\lambda_{2}\left(\mathrm{x}-\mu_{2}\right)\right]}+\mathrm{a}_{3}^{-\alpha_{3}\left(\mathrm{x}-\mu_{3}\right)-\exp \left[\lambda_{3}\left(\mathrm{x}-\mu_{3}\right)\right]} .
$$

The estimated parameters of this schedule ${ }^{\S}$ fitted to the age profile of migration from California to Arizona are:

$$
\hat{\mathrm{N}}_{\mathrm{CA}, \mathrm{AZ}}(\mathrm{x})=0.006+0.07^{-0.05 \mathrm{x}}+0.23^{-0.11(\mathrm{x}-23.2)-\exp [0.11(\mathrm{x}-23.2)]}+0.000004^{-0.5(\mathrm{x}-92.6)-\exp [0.06(\mathrm{x}-92.6)]}
$$

This model resulted in an $\mathrm{R}^{2}$ of 0.9965 and all of the coefficient t-statistics, except for the ones associated with the elderly retirement peak, are significant at the 0.05 level. The reason why the t-statistics for the elderly age groups are not significant is not clear. It probably has to do with the fact that the majority of the data are represented by the labor force curve. The curve fitted to the observed data is set out in Figure 8.

\footnotetext{
$\S$ These parameters were fitted using the software program TableCurve2D. This program allows a maximum of 10 parameters to be estimated in its User-Defined Program. To get around this, the constant $\left(\mathrm{a}_{0}\right)$ was set to the minimum observed value of the standardized data (i.e., 0.006).
} 


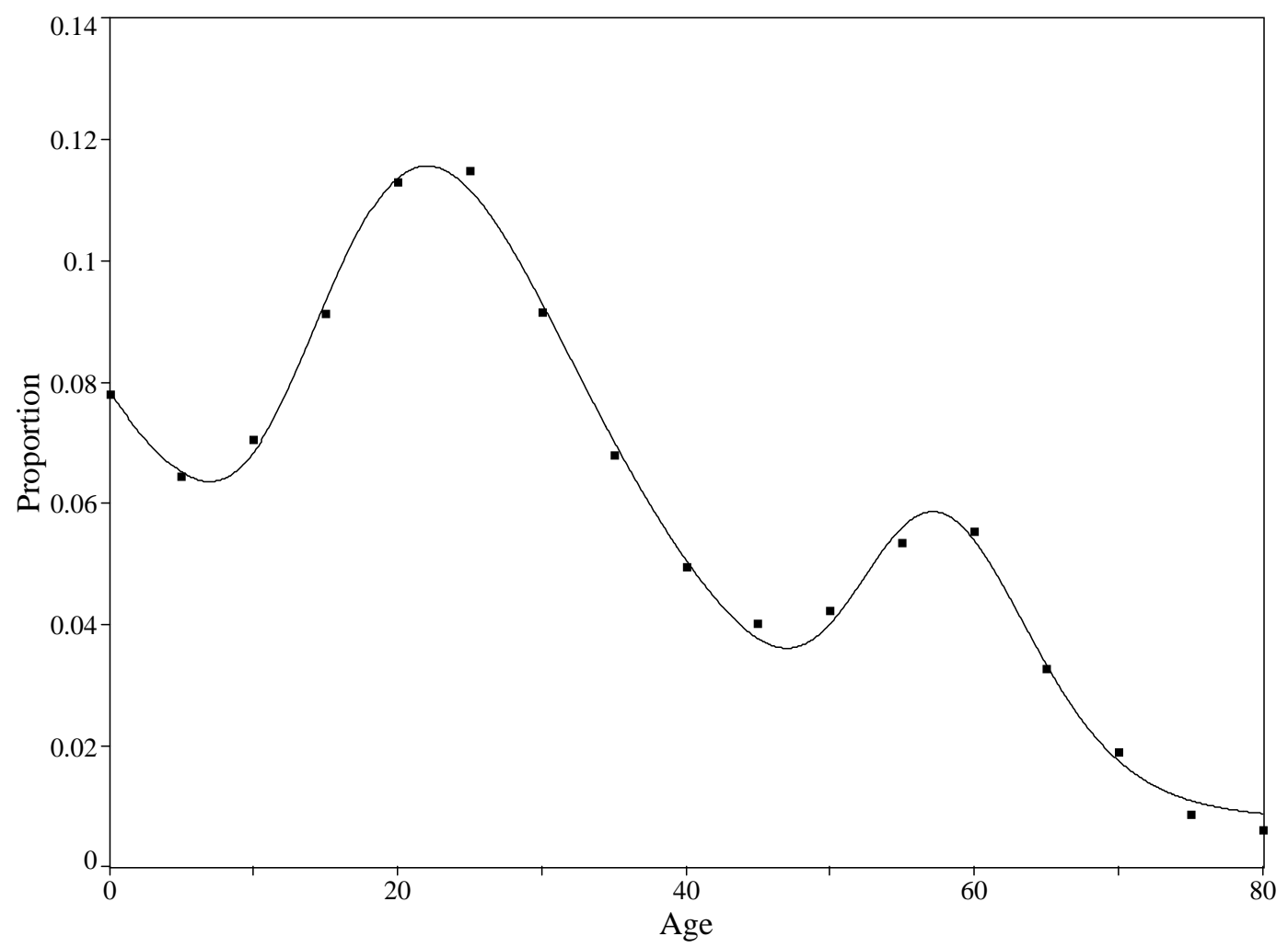

Figure 8. An eleven parameter multiexponential model migration schedule fitted to the observed age profile of migration from California to Arizona, 1985-1990

\section{Modeling Families of Age-Specific Migration}

Several age-specific models of migration are presented in this subsection. The main assumption is that the levels of aggregate origin-destination-specific migration are known. The consequences of using different age-specific models are assessed. The models are based on different scenarios regarding available age-specific information about migration. All of the models make use of a simple and straightforward strategy to translate aggregate migration flows into age-specific flows. This relationship makes use of standardized-to-unit-area age profiles of migration, i.e.: 


$$
\mathrm{n}_{\mathrm{ij}}(\mathrm{x})=\mathrm{n}_{\mathrm{ij}} * \mathrm{~N}_{\mathrm{ij}}(\mathrm{x}),
$$

where $n_{\mathrm{ij}}(\mathrm{x})$ is an age-specific migration flow from $\mathrm{i}$ to $\mathrm{j}, \mathrm{n}_{\mathrm{ij}}$ is the aggregate migration flow from $\mathrm{i}$ to $\mathrm{j}$, and $\mathrm{N}_{\mathrm{ij}}(\mathrm{x})$ is the corresponding standardized-to-unit-area age profile of migration. For example, consider the four standardized age profiles from California to Colorado, Utah, Montana, and Arizona set out in Figure 4. The observed migration levels of those age profiles were $62,397,38,356,11,990$, and 136,465 , respectively. When these numbers are multiplied by the standardized age profiles, the result is the set of age-specific migration flows presented in Figure 9. Notice that the migration flow to Arizona was the largest and that it had a retirement peak and that the migration flow to Montana was the smallest. Throughout this section, the observed age patterns of these four flows are compared to the predicted flows. The models actually estimate all of the 196 age patterns. These four flows are presented for illustration purposes and because they represent different shapes of age-specific migration. 


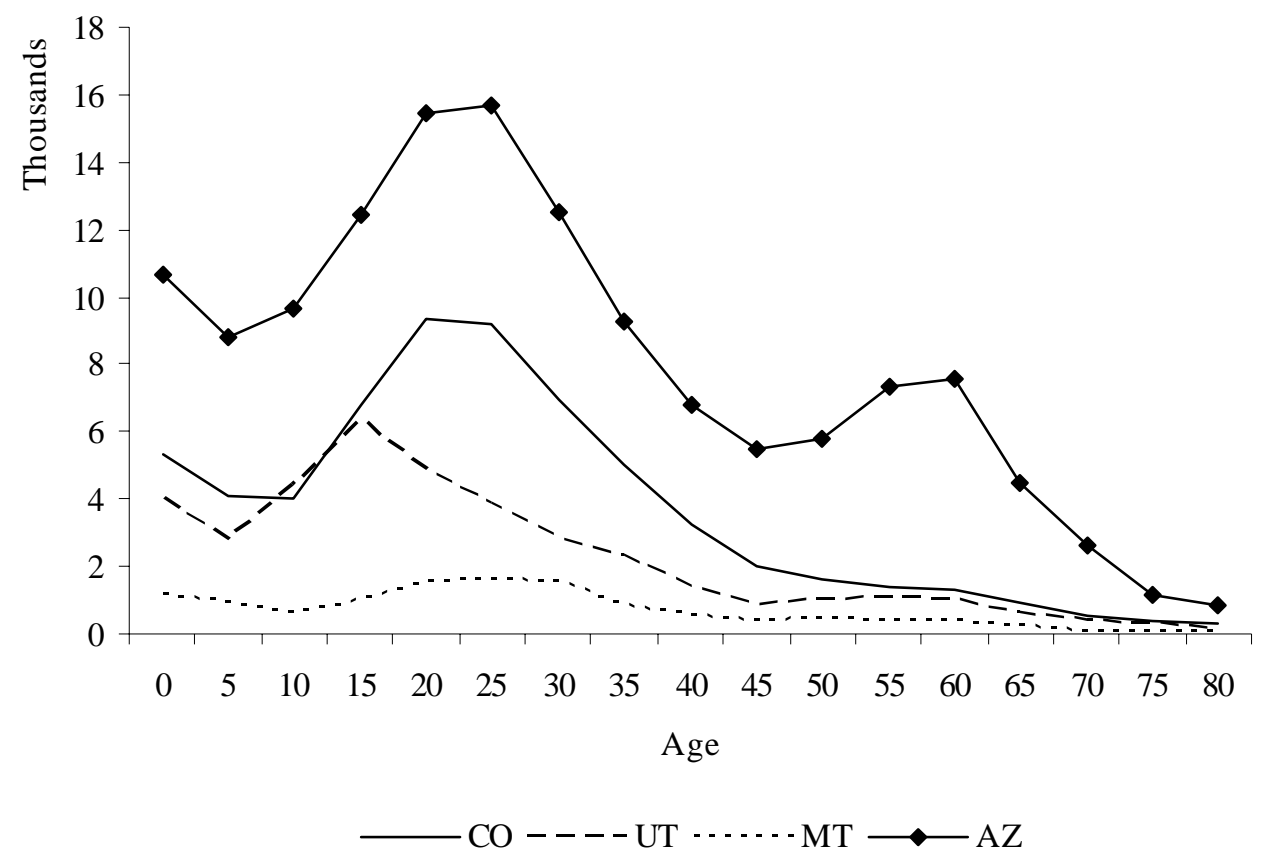

Figure 9. Age-specific migration flows from California to Colorado, Utah, Montana, and Arizona, 1985-1990

When it comes to the availability of age-specific data, there could be several possible situations. In the worse case scenario, no age-specific data are available. Here, one has no choice but to make a "best educated guess" based on the characteristics of the location and what the literature on this topic suggests (e.g., Plane and Heins 2003). In other situations, observed agespecific data might be available, but only for aggregate levels of age-specific in-migration and out-migration. Or, some place-to-place age-specific data might be available, but not all. Another situation that could arise is one in which the data were obtained from a relatively small sample of the population. These data might not exhibit the expected age-specific regularities often observed with migration data. In such situations, it might make sense to smooth the data using model migration schedules. Finally, a situation might arise where one has information about the shapes of the age profiles (i.e., retirement locations), but not necessarily the observed age-specific data 
for the period of interest. The estimations of the age-specific flows carried out in this section attempt to cover several of these hypothetical situations.

Four families of age-specific migration have been identified in the observed migration data. For the purpose of testing the robustness of these age-specific families of migration, model migration schedules were fitted to the observed data. More specifically, two sets of age profiles were used to represent the observed data. In the first case, a model migration schedule was fitted to all of the 196 observed standardized age profiles of migration to come up with an average for the entire data set. In the second case, four separate model migration schedules were fitted to the observed standardized age profiles of migration corresponding to the standard (i.e., 118 flows), young standard (i.e., 34 flows), old standard (i.e., 35 flows), and elderly retirement peak (i.e., 9 flows) families of age-specific migration. The resulting model schedules represented the average standardized age profile for each of the four families.

Seven-parameter model migration schedules were used to estimate the average standard, young standard, old standard, and "all flows" age profiles of migration. The average elderly retirement peak age profile of migration, on the other hand, was estimated using an eleven parameter model. In all cases, the model schedules were fit to the observed standardized-to-unitarea age-specific migration flows. The parameters of the five model migration schedules of agespecific migration are set out in Table 1. The "all flows" schedule captured 86 percent of the observed standardized age-specific patterns of migration. The other schedules representing the standard, young standard, old standard, and elderly retirement peak age profiles of migration captured 89 percent, 90 percent, 87 percent and 94 percent of the corresponding observed age profiles of migration, respectively. These schedules were fitted assuming equal weight for each profile of age-specific migration and represent the average of those profiles. Another strategy 
would be to sum up the flows for each of the respective families, standardize them, and then apply model migration schedules. This would give more weight to age profiles of larger flows (i.e., from and to California) and potentially improve the overall fit.

Table 1. Parameters of model migration schedules fitted to age profiles of interstate migration in the U.S. West, 1985-1990

\begin{tabular}{|c|c|c|c|c|c|c|}
\hline Curve & Parameter & All flows & Standard & $\begin{array}{l}\text { Young } \\
\text { Standard }\end{array}$ & $\begin{array}{l}\text { Old } \\
\text { Standard }\end{array}$ & $\begin{array}{l}\text { Elderly } \\
\text { Retirement }\end{array}$ \\
\hline Constant & $\mathrm{a}_{0}$ & 0.00248 & 0.00000 & 0.00000 & 0.00000 & 0.00417 \\
\hline Pre-labor & $a_{1}$ & 0.09553 & 0.09734 & 0.09882 & 0.10048 & 0.07458 \\
\hline Force & $\alpha_{1}$ & 0.04454 & 0.03752 & 0.04682 & 0.03078 & 0.04559 \\
\hline Labor & $a_{2}$ & 0.26952 & 0.27633 & 0.18771 & 0.23242 & 0.21018 \\
\hline Force & $\alpha_{2}$ & 0.09849 & 0.10792 & 0.06272 & 0.10829 & 0.07602 \\
\hline & $\mu_{2}$ & 18.06952 & 17.68602 & 11.33097 & 21.24397 & 17.92130 \\
\hline & $\lambda_{2}$ & 0.15656 & 0.19563 & 0.33746 & 0.17001 & 0.14497 \\
\hline Post-labor & $\mathrm{a}_{3}$ & & & & & 0.00000 \\
\hline Force & $\alpha_{3}$ & & & & & 0.50056 \\
\hline & $\mu_{3}$ & & & & & 92.16927 \\
\hline & $\lambda_{3}$ & & & & & 0.06163 \\
\hline \multirow{2}{*}{\multicolumn{2}{|c|}{$\mathrm{R}^{2}$}} & 0.86332 & 0.89423 & 0.89651 & 0.86718 & 0.93946 \\
\hline & Standard error & 0.01874 & 0.01689 & 0.01686 & 0.01779 & 0.00879 \\
\hline \multirow{2}{*}{\multicolumn{2}{|c|}{ Number of observations }} & 3,332 & 2,006 & 578 & 595 & 153 \\
\hline & & 196 & 118 & 34 & 35 & 9 \\
\hline
\end{tabular}

The actual fitted migration curve used to represent the average of all of the 196 observed standardized-to-unit-area migration flows is set out in Figure 10. The curve was estimated using the seven-parameter multiexponential model migration schedule. The vertical bars in the graph 
represent the observed data for each age group. Note the line fitted through these data is a continuous function and that there is much variation in the age-specific data.

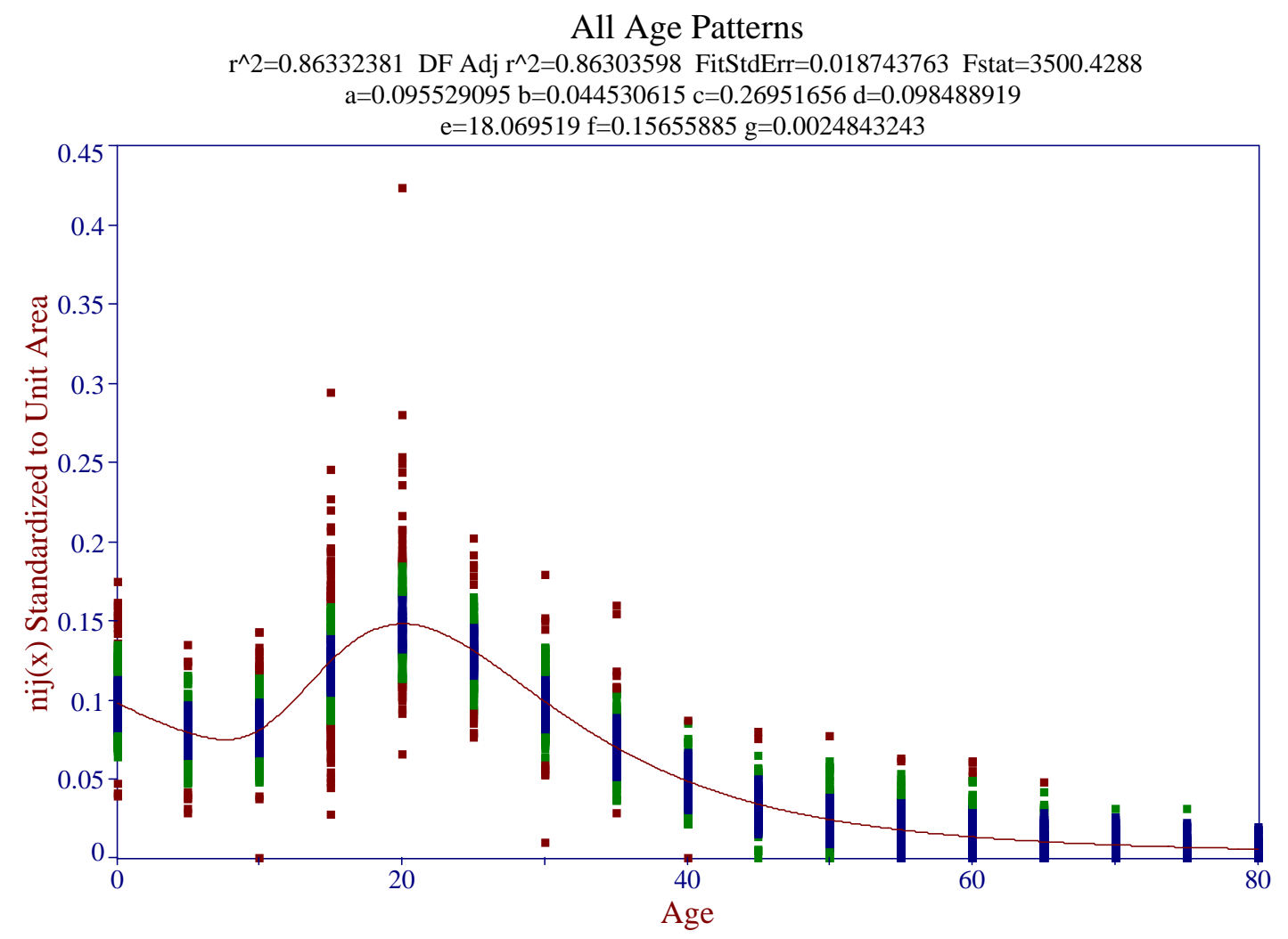

Figure 10. Model migration schedule of observed age profiles of migration in the U.S. West, 1985-1990

The fitted migration curves to the age-specific data associated with the standard (top left), young standard (top right), old standard (bottom left), and elderly retirement (bottom left) age profiles are set out in Figure 11. The fitted curves represent the averages for each of the familyspecific age profiles of migration. These graphs include 95 percent confidence intervals for both the predicted values and the fitted regression curve. 

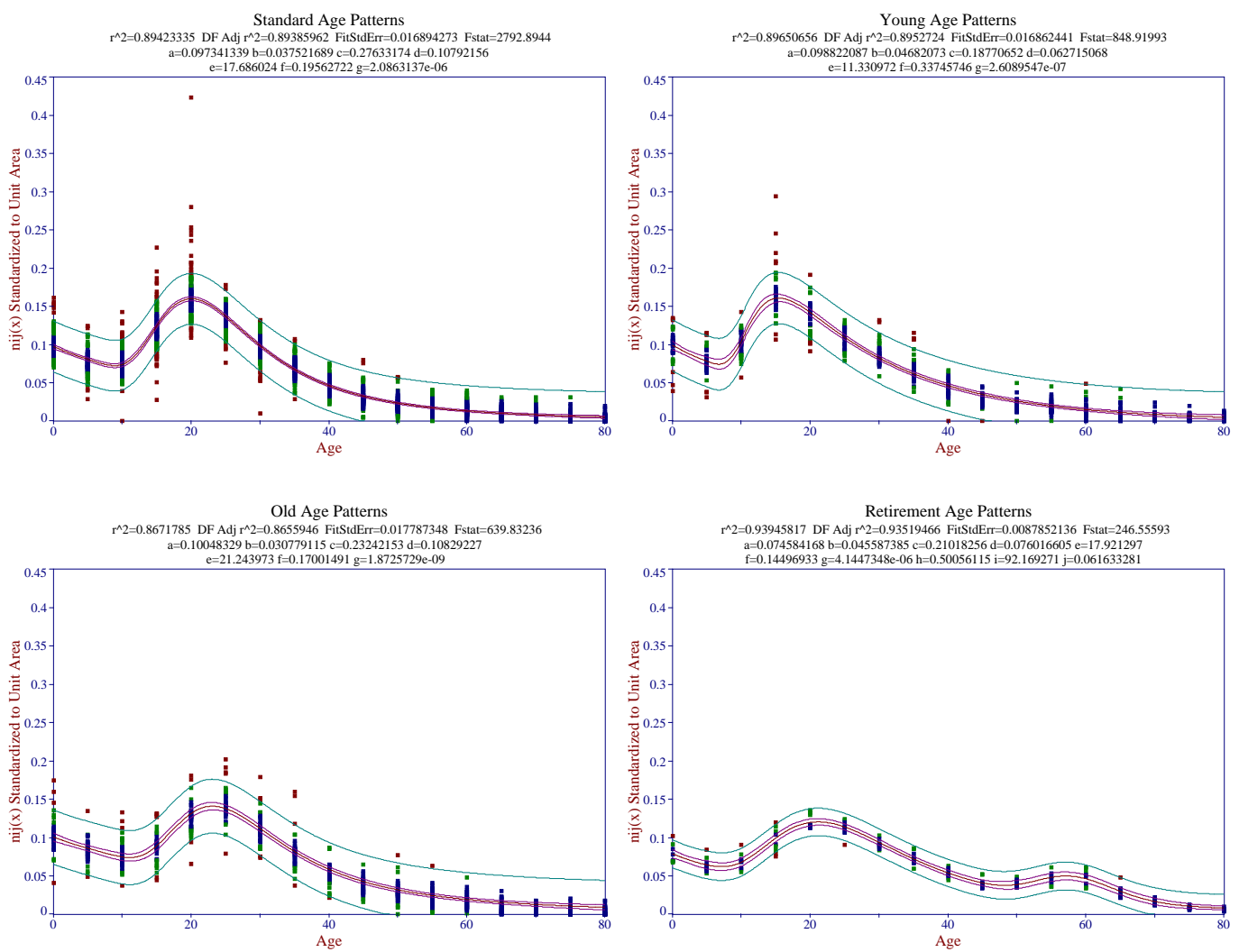

Figure 11. Model migration schedules of observed standard, young standard, old standard, and elderly retirement age profiles of migration in the U.S. West, 1985-1990

Once the five age profiles of migration were estimated, they had to be adjusted (slightly) so that they summed to unity. These schedules are set out in Figure 12. Notice the differences in the shapes. For example, the retirement peak curve in a standardized-to-unit-area curve is associated with a lower labor force peak, because more weight is included in the retirement years. The young standardized curve's labor force peak is shifted to the left, whereas the old standardized curve's labor force peak is shifted to the right. And, finally, the three curves without a retirement peak have basically the same shape after age 35. 


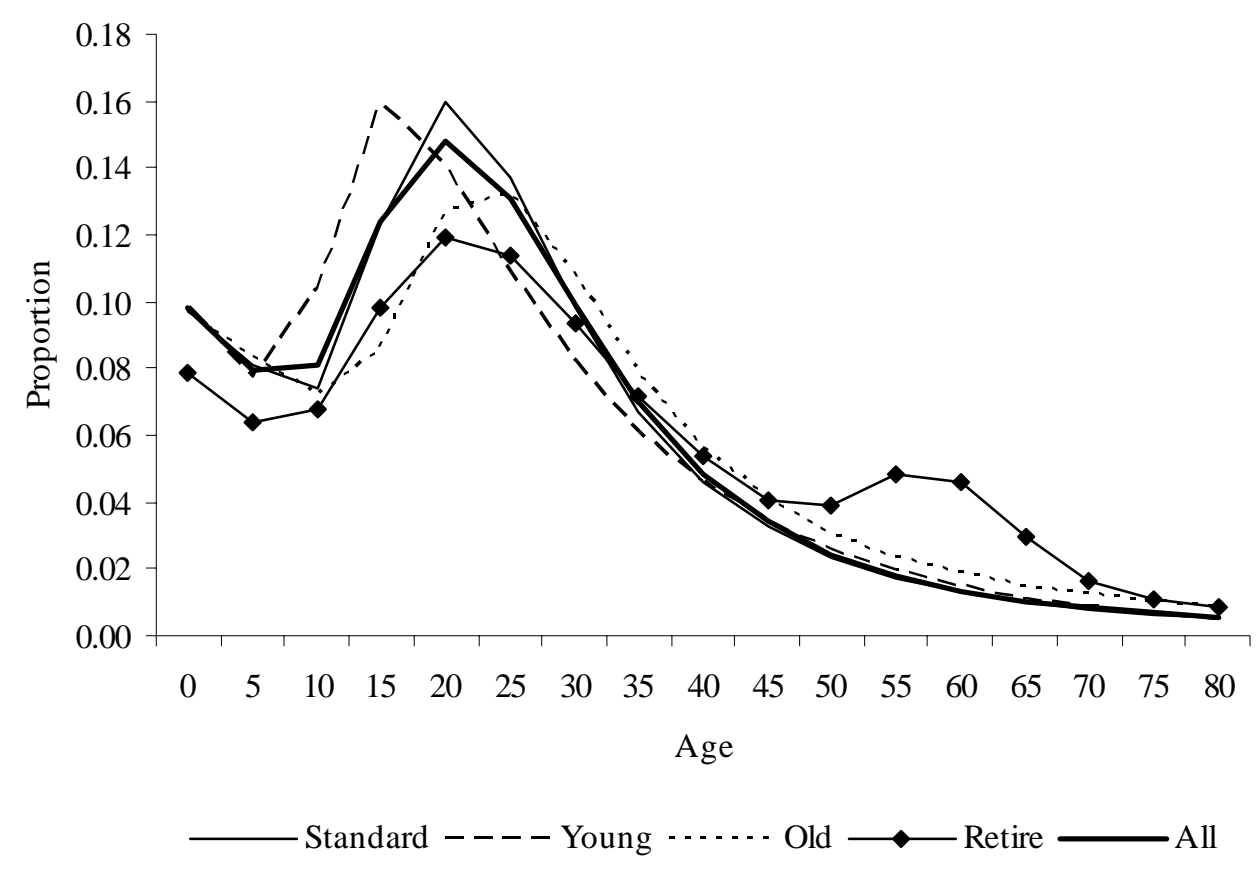

Figure 12. Model migration schedules (standardized to unit area) of observed age profiles of interstate migration in the U.S. West, 1985-90

The purpose of fitting curves to the observed data was to test whether the data can be simplified for use in estimating numerous age profiles of migration. The main question is basically whether these four schedules representing four families of age-specific migration can be used accurately to represent the real data. If so, then the modeling process becomes much simpler. For example, all one needs to know to estimate the migration flows is some auxiliary data that describes the type of schedule to be used.

Next, several hypothetical situations with regard to available data are tested. The first situation represents one in which only the observed national age profile of interstate migration is known. The second situation is one in which the observed age profiles of aggregate in-migration are known. The third situation is one in which the observed age profiles of aggregate outmigration are known. These first three situations assume some level of observed data is provided. 
The fourth situation applies the "all flows" model schedule (Figure 12). And, the fifth situation applies the four model migration schedules representing the four families of age-specific migration observed in the data. Here, the assumption is that the relationship is known --- agespecific migration from $\mathrm{i}$ to $\mathrm{j}$ has a particular shape. This represents a situation, for example, where a researcher expects the migration flow between, say, California and Arizona to have a retirement peak because of the existence of many elderly residing in Arizona who came from California. Likewise, one might suspect that migration flows into Utah might exhibit a young standard age profile of migration because of recent enumerations that showed a "bulge" in the age profile of the population stock data in the 15-19 group not explained by past fertility patterns (i.e., cohort aging).

The standardized age profiles used in each of the five scenarios discussed above were multiplied by the observed aggregate origin-destination-specific flows to obtain the corresponding predicted age-specific migration flows. These flows were then compared with the observed. The $\mathrm{R}^{2}, \chi^{2}$, and $\mathrm{G}^{2}$ goodness-of-fit statistics calculated from results are set out in Table 2. All of the $\mathrm{R}^{2}$ values are very high --- above 96 percent of the variation in the observed data is explained in each of the five models. The predictions that used the aggregate in-migration and out-migration age profiles for each state gave the best results. The observed total migration age profile gave better results than the model schedule fitted to the 196 age profiles, which suggests that the age-profiles should be weighted before fitting model migration schedules to them. The mixture model migration schedule scenario (i.e., the one that applied the four model schedules representing the four families of age-specific migration) did a better job than the "all flows," but not better than using just a standardized schedule obtained from the national level of migration. The results for the mixture model might have been improved had the model schedules 
been fitted to four aggregate schedules (representing each of the four families) rather than assuming equal weight among many similar standardized schedules.

Table 2. Comparison of different age-specific models used to predict age profiles of interstate migration in the U.S. West, 1985-1990

\begin{tabular}{llllll}
$\begin{array}{l}\text { Goodness- } \\
\text { of-Fit }\end{array}$ & \multicolumn{3}{c}{ Observed Aggregate } & & \multicolumn{2}{c}{ Model Schedule } \\
Statistic & Out & In & Total & Mixture & All Flows \\
\hline & & & & & \\
$\mathrm{R}^{2}$ & 0.9914 & 0.9921 & 0.9843 & 0.9716 & 0.9687 \\
$\chi^{2}$ & 298,158 & 326,194 & 607,885 & 526,369 & 803,468 \\
$\mathrm{G}^{2}$ & 122,202 & 141,957 & 242,677 & 227,629 & 317,841
\end{tabular}

The results presented in Table 2 represent the overall fit of the five models used to predict all 196 age profiles of migration. Next, only the five predicted age-specific migration flows from California to Arizona, Colorado, Montana, and Utah are selected out and compared with the corresponding observed flows. The purpose is for obtaining a better feel for how the predictions fit the observed data.

Table 3. Comparison of different age-specific models ${ }^{*}$ used to predict age profiles of migration from California to Arizona, Colorado, Montana, and Utah, 1985-1990

\begin{tabular}{lrrrrr}
$\begin{array}{c}\text { Migration } \\
\text { Flow }\end{array}$ & Out & \multicolumn{2}{c}{ Observed Aggregate } & \multicolumn{2}{c}{ Model Schedule } \\
In & Total & Mixture & All Flows \\
\hline CA to AZ & 0.9303 & 0.9316 & 0.8690 & 0.9855 & 0.8717 \\
CA to CO & 0.9924 & 0.9700 & 0.9430 & 0.9675 & 0.9613 \\
CA to MT & 0.9397 & 0.9233 & 0.8249 & 0.9535 & 0.8836 \\
CA to UT & 0.7287 & 0.9836 & 0.8788 & 0.9722 & 0.8546 \\
$*$ & & & & \\
\end{tabular}


Interestingly, when the goodness-of-fit values are compared for the specific flows, the mixture model that uses the four families of model schedules produces the best results -- except for the California to Colorado flow, where the out-migration model worked best. In terms of the worst fits, the total schedule tended to be the worst, except for California to Utah, where the aggregate out-migration model was the worst. The message from these results is that, while the overall level produces a better "average" fit, having more information about the shape of the ageprofile improves individual fits, at least for the four cases presented here.

The age-specific graphs set out below in Figure 13 illustrate visually the results set out in Table 3. In Figure 13A, we see that the only age profile that is really close to the observed is the one from the model schedule mixture model (MS-Mix). The other age profiles tend to overpredict the labor force peak and under-predict the observed retirement peak. For the California to Colorado age profiles set out in Figure 13B, all of the flows, while fitting the observed data fairly well, have a labor force peak that is slightly shifted to the left of the observed. Here, the aggregate out-migration curve does a good job of fitting the observed data. The predictions for the California to Montana flow vary substantially from the observed. This is due to it being a fairly unusual age profile in that it has a wide labor force peak. The best model for this data is the model schedule mixture model. Finally, the predictions for the California to Utah age patterns show that only two models come close to capturing its relatively young labor force peak - the mixture model schedule model and the aggregate in-migration model. 


\section{CA to $\mathrm{AZ}$}

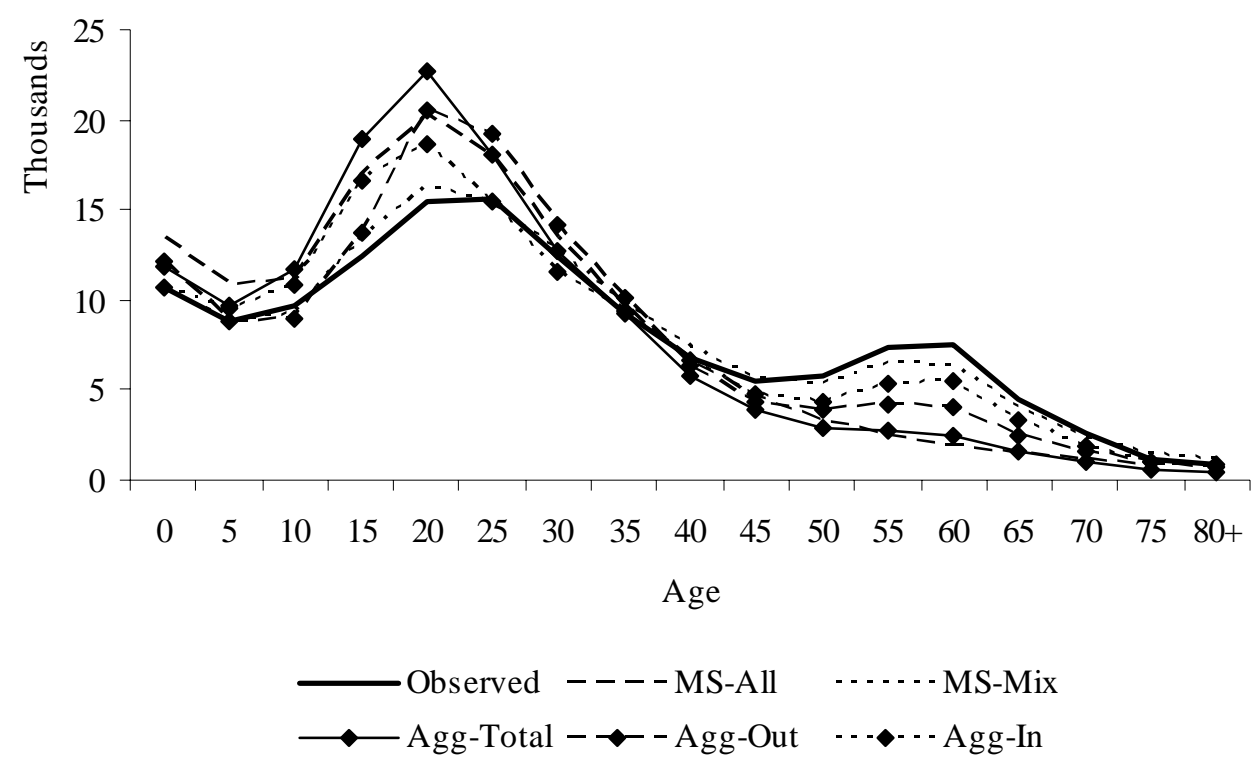

Figure 13A The observed and predicted migration flows from California to Arizona, 1985-1990

CA to CO

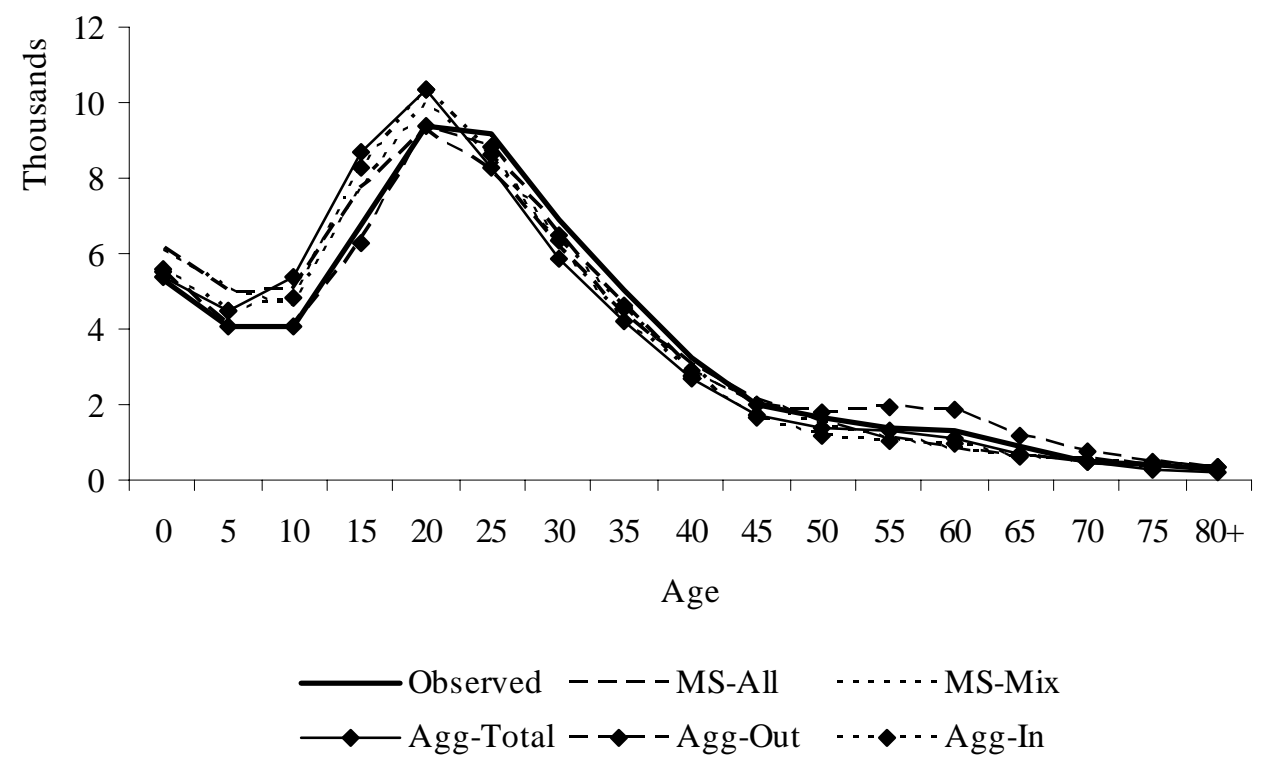

Figure 13B The observed and predicted migration flows from California to Colorado, 19851990 


\section{CA to MT}

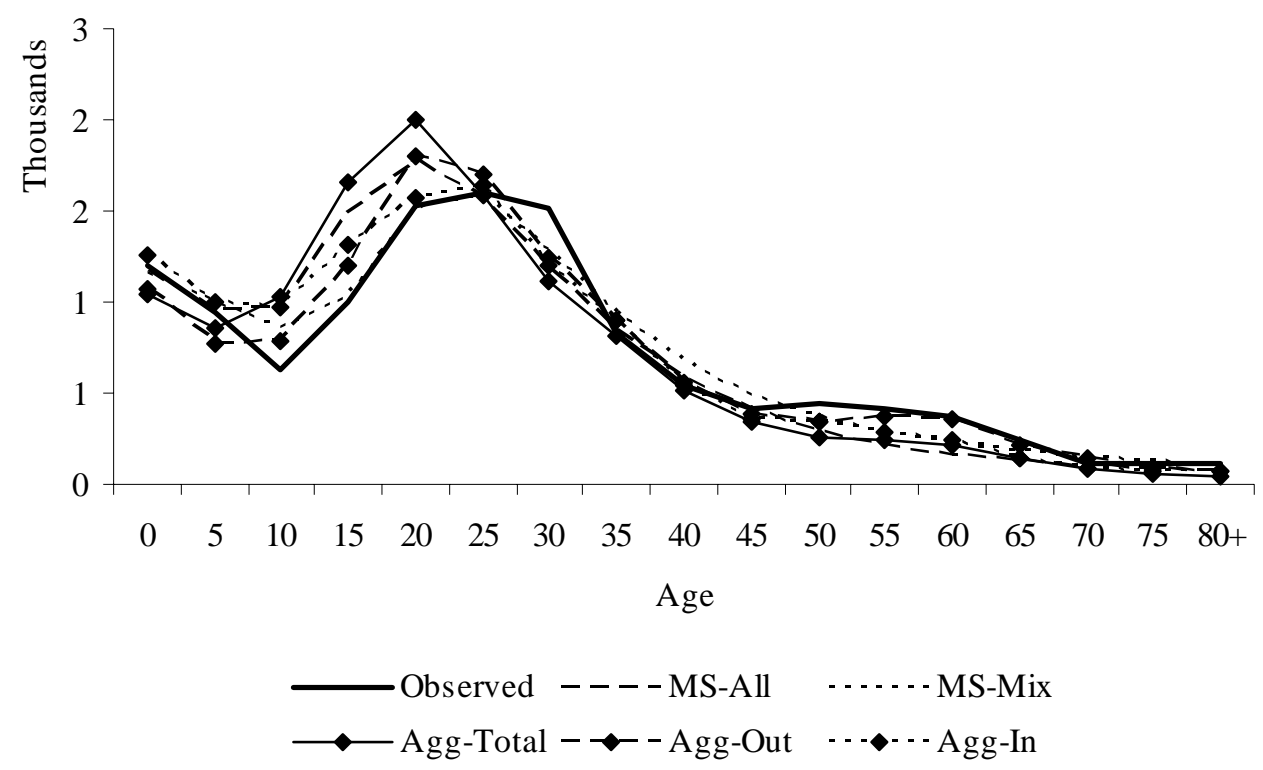

Figure 13C The observed and predicted migration flows from California to Montana, 1985-1990

CA to UT
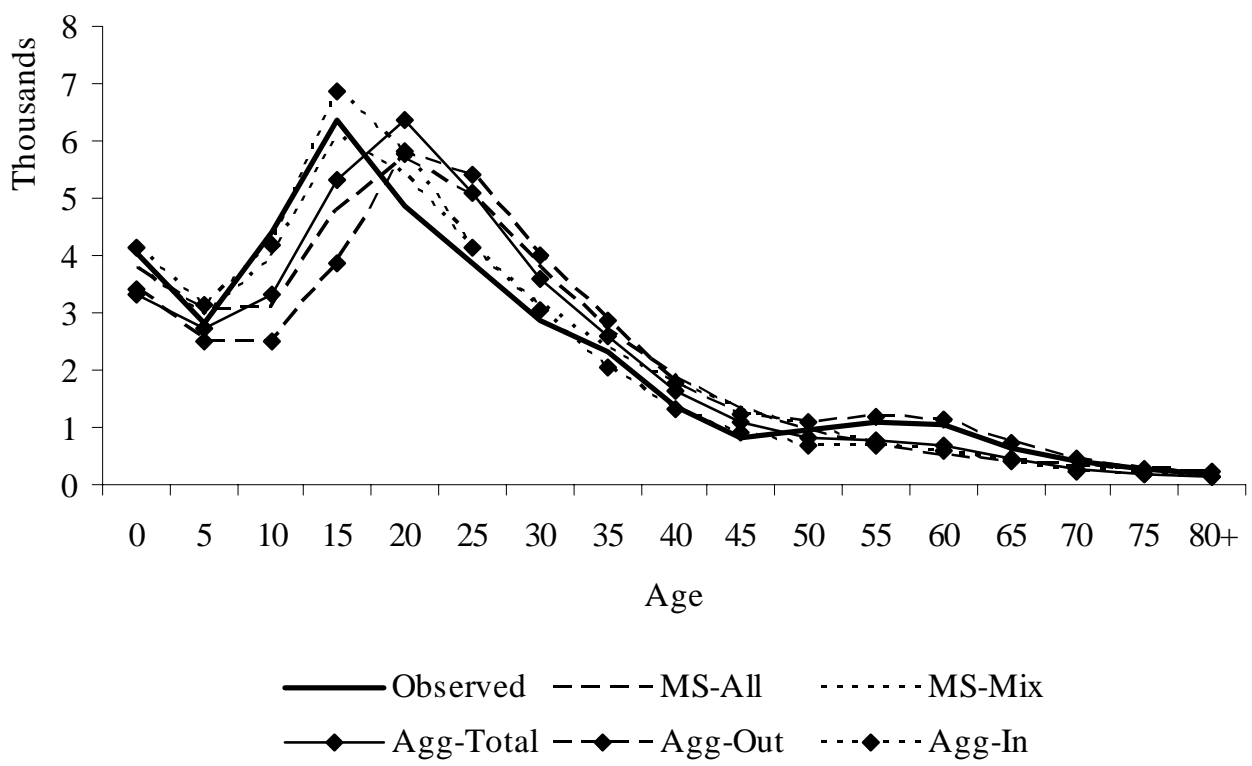

Figure 13D The observed and predicted migration flows from California to Utah, 1985-1990 


\section{Discussion and Conclusion}

Model migration schedules (Rogers and Castro 1981a) were applied, in this paper, to represent specific known patterns of migration. In particular, four model migration schedule families were used to represent 196 flows of migration. This finding simplified the modeling process, by assuming that all one required to model age patterns of migration was some information about the likely shapes of the age profiles. Another useful finding was that the aggregate in-migration and out-migration profiles captured most of the age patterns. Often, origin-destination-specific age patterns of migration are not available (e.g., Intra-European migration data from Eurostat only include age patterns of immigration and emigration). This study suggests that it is quite reasonable to expect that regularities found in observed age patterns of migration can be used to effectively estimate missing or inadequate data.

Four directions of further study are evident. First of all, how stable are the observed age patterns over time? Our preliminary examination of temporal stability suggests that many flows continue to exhibit a surprising degree of constancy in age profiles. Tobler (1995), for example, found that sufficient stability exists for the Rogers-Castro (1981a) model schedule be called one of the "laws" of migration. Rogers and Raymer (1999) found evidence of temporal stability in the interregional migration patterns of the foreign-born in the United States reported by the 1960, 1970, 1980, and 1990 censuses. But more definitive findings are needed.

Second, our focus has been directed at internal migration age patterns. What about international patterns? Rogers and Raymer (1999), for example, found that U.S. immigration age profiles conformed to the Rogers-Castro (1981a) model schedule during the 1955-1990 time period. In this volume, Raymer presents similar evidence for population movements in the European Union. But, once again, more definitive findings are needed. 
Third, what about migration age patterns in the less-developed countries? Are there reasons to suspect a lack of conformity? Evidence gathered to data show that the Rogers-Castro (1981a) model migration schedule also describes migration age patterns in the less-developed world. Rogers et al. (2004) present supporting evidence for Indonesia. Partida (2004) does the same for Mexico. It is likely, therefore, that age patterns of migration in less-developed countries also exhibit the standard model migration schedule profiles. But further studies are warranted.

Finally, there is the question regarding the feasibility of indirect estimation of migration. Demographic techniques for indirectly estimating fertility and mortality age patterns are welldeveloped and widely used in the less-developed world. A somewhat dated United Nations manual on the topic is still the best single source for a review of these procedures (United Nations 1983). Unfortunately it totally ignores migration. Nevertheless, relatively resent efforts to develop such techniques are promising and suggest that the development of a formal methodology for such estimation methods is possible with further research (Raymer and Rogers 2005; Rogers and Jordan 2004).

In conclusion, empirical regularities in age pattern characterize observed migration schedules in ways that are no less important than the corresponding well-established regularities in observed fertility or mortality schedules. Capturing such regularities in the form of model schedules could be used to assess the reliability of empirical migration data and indicate appropriate strategies for their correction, and they also may be used to help resolve problems caused by missing data.

Although the basic age profile of migration seems to hold over time, its level and shape may change. Such changes become reflected in temporal variations exhibited by the parameters of the model migration schedule. 
The impacts of such changes in levels and age profiles may be analyzed conveniently by means of population projections. Multiregional/multistate projection models assess the numerical consequences, to an observed or hypothetical population, of a particular set of assumptions regarding future patterns of mortality, fertility, and interregional transfers.

They generally need to keep track of enormous amounts of data. The disaggregations incorporated in such projections are introduced either because forecasts of the specified population subgroups are important in their own right, or because it is believed that simple and regular trends are more likely to be discovered at relatively higher levels of disaggregation.

High levels of disaggregation permit a greater flexibility in the use of the projections by a wide variety of users; they also often lead to a detection of greater consistency in patterns of behavior among more homogeneous population subgroups. But greater disaggregation requires the estimation of even greater numbers of data points, both those describing initial population stocks and those defining the future rates of events and flows that are expected to occur. The practical difficulties of obtaining and interpreting such data soon outstrip the benefits of disaggregation.

Model schedules offer a means for condensing the amount of information to be specified as assumptions. They also express this condensed information in a language and variables that are more readily understood by the users of the projections, and they provide a convenient way of associating the variables to one another, extrapolating them over time, and relating them to variables describing the economic environment that underlies the projections.

The use of parameterized model schedules in the population projection process allows one to develop an effective description of how the components of demographic change are assumed to vary over time in terms of a relatively few parameters. To the extent that the 
assumptions correctly anticipate the future, the projection foretells what indeed comes to pass. And insofar as the parameters are interpretable by non-demographer users of the projection, they make possible the assessment of the reasonableness of a set of assumptions instead of a set of projected population totals.

As Keyfitz (1972) correctly observed a trend extrapolation of each age-specific rate in a population projection is an excessive concession to flexibility that can readily produce erratic results. On the other hand, to assume that change in a set of rates occurs uniformly at all ages is to go against experience. Model schedules in general, and model migration schedules in particular, offer a way of introducing flexibility, while at the same time retaining the interdependence between the rates of a particular schedule (Rogers 1986). 


\section{References}

Bates J and I Bracken. 1982. Estimation of migration profiles in England and Wales. Environment and Planning A, 14:889-900.

---. 1987. Migration age profiles for local authority areas in England, 1971-1981. Environment and Planning A, 19:521-535.

Holmberg I, ed. 1984. Model migration schedules: The case of Sweden. Stockholm: Scandinavian Demographic Society.

Kawabe H. 1990. Migration rates by age group and migration patterns: Application of Rogers' migration schedule model to Japan, The Republic of Korea, and Thailand. Tokyo: Institute of Developing Economies.

Levin ML and S Mitra. 1994. Research methods: Visualization in the numeric solution of complex nonlinear equations in mathematical demography. Social Science Computer Review, 12(4):625-640.

Liaw K-L and DN Nagnur. 1985. Characterization of metropolitan and nonmetropolitan outmigration schedules of the Canadian population system, 1971-1976. Canadian Studies of Population, 12(1):81-102.

Little JS and A Rogers. 2006. What can the age composition of a population tell us about the age composition of its outmigrants? Presented at Western Regional Science Association, Santa Fe, New Mexico.

Partida Bush V. 2004. Inferring migration flows from birthplace-specific population stocks: The case of Mexico. Presented at Colorado Conference on the Estimation of Migration, Estes Park, Colorado.

Plane DA and F Heins. 2003. Age articulation of U.S. inter-metropolitan migration flows. The Annals of Regional Science, 37:107-130.

Potrykowska A. 1986. Modelling inter-regional migrations in Poland, 1977-81. Papers of the Regional Science Association, 60:29-40.

Raymer J and A Rogers. 2005. Using age and spatial flow structures in the indirect estimation of migration streams. Southampton Statistical Sciences Research Institute Applications and Policy Working Paper A05/07, University of Southampton, Southampton, England.

Rogers A. 1986. Parameterized multistate population dynamics and projections. Journal of the American Statistical Association, 81(393):48-61.

---. 1988. Age patterns of elderly migration: An international comparison. Demography, 25(3):355-370. 
Rogers A and LJ Castro. 1981. Age patterns of migration: Cause-specific profiles. In Advances in multiregional demography, RR-81-6, Rogers A, ed. Laxenburg, Austria: International Institute for Applied Systems Analysis.

---. 1981a. Model migration schedules. RR-81-30, International Institute for Applied Systems Analysis, Laxenburg, Austria.

Rogers A and L Jordan. 2004. Estimating migration flows from birthplace-specific population stocks of infants. Geographical Analysis, 36(1):38-53.

Rogers A and JS Little. 1994. Parameterizing age patterns of demographic rates with the multiexponential model schedule. Mathematical Population Studies, 4(3):175-194.

Rogers A, S Muhidin, L Jordan and M Lea. 2004. Indirect estimates of age-specific interregional migration flows in Indonesia based on the mobility propensities of infants. Presented at Colorado Conference on the Estimation of Migration, Estes Park, Colorado.

Rogers A and S Rajbhandary. 1997. Period and cohort age patterns of US migration, 1948-1993: Are American males migrating less? Population Research and Policy Review, 16:513530.

Rogers A and J Raymer. 1999. Estimating the regional migration patterns of the foreign-born population in the United States: 1950-1990. Mathematical Population Studies, 7(3):181216.

---. 1999. Fitting observed demographic rates with the multiexponential model schedule: An assessment of two estimation programs. Review of Urban and Regional Development Studies, 11(1):1-10.

Rogers A and JF Watkins. 1987. General versus elderly interstate migration and population redistribution in the United States. Research on Aging, 9(4):483-529.

Tobler W. 1995. Migration: Ravenstein, Thornthwaite, and beyond. Urban Geography, 16(4):327-343.

U.S. Census Bureau. 1993. 1990 County to county migration, Special Project 312. U.S. Government Printing Office, Washington, DC.

United Nations. 1983. Manual X: Indirect techniques for demographic estimation. New York: Department of International Economic and Social Affairs. 


\section{Appendix: Fitting Model Migration Schedules}

TableCurve2D (version 5.0) is an automated curve fitting and equation discovery program that has been designed for a variety of scientific uses. In this program, the multiexponential model migration schedule can be specified using a User Defined Function that allows up to 10 parameters to be estimated. This program also has visualization features that permit the user to see how the model is affected by changes in individual parameter values. Rogers and Raymer (1999) compared the results and procedures of this software with those of MODEL (Rogers and Little 1994) --- a more specialized software designed for estimating age-specific fertility, mortality, and migration using the multiexponential model. Rogers and Raymer found that both programs produced the same results, but that TableCurve2D had several advantages over MODEL, particularly the procedural aspects of the modeling process, which are more userfriendly. For example, imagine that a problem arises in the specified initial estimates, which is quite common when dealing with so many parameters. In TableCurve2D, it is possible to partition the data and then to derive initial estimates for different sections of the curve. Levin and Mitra (1994) demonstrated this with the TableCurve2D program using mortality data. Note, most standard statistical software (e.g., SPSS or Stata) have non-linear regression routines. These can readily be used to estimate the 7-parameter schedule, however one needs reasonable initial estimates. Fitting the 9-, 11-, or 13-parameter schedules is much more complicated. Here, a graphical interface like the one in TableCurve2D is very useful for obtaining the initial estimates. 